\title{
A construção dos conceitos de uso nocivo ou preju- dicial e dependência de álcool: considerações para o campo de atenção e cuidado à saúde
}

\section{The construction of concepts of harmful use and dependence of alcohol: some considerations to the field of health attention and care}

\author{
Ana Lucia Marinho Marques', Elisabete Ferreira Mângia²
}

\begin{abstract}
MARQUES, A. L. M.; MÂNGIA, E. F. A construção dos conceitos de uso nocivo ou prejudicial e dependência de álcool: considerações para o campo de atenção e cuidado à saúde. Rev. Ter. Ocup. Univ. São Paulo, v. 21, n. 1, p. 10-14, jan./abr. 2010.

RESUMO: Este artigo busca apresentar um breve histórico do processo de conceituação do uso considerado como nocivo ou prejudicial e da denominada dependência de álcool, no campo da saúde. Com isto, espera-se fornecer elementos para problematizar a apropriação e o uso de tais conceitos e de modelos teórico-práticos construídos em torno a esta questão, no processo de formulação de práticas de atenção e cuidado à saúde de sujeitos com problemáticas decorrentes do uso de substâncias psicoativas.
\end{abstract}

DESCRITORES: Transtornos relacionados ao uso de substâncias. Alcoolismo. Práticas em saúde. Concepcões e abordagens.

\footnotetext{
1. Terapeuta Ocupacional do Curso de Terapia Ocupacional da FMUSP, Mestre pelo Programa de Pós-Graduação em Ciências da Reabilitação da FMUSP.

2. Profa. Dra. do Departamento de Fisioterapia, Fonoaudiologia e Terapia Ocupacional da FMUSP.

Endereço para correspondência: Departamento de Fisioterapia, Fonoaudiologia e Terapia Ocupacional da FMUSP. Rua Cipotânea, 51, Cidade Universitária, São Paulo, SP, CEP: 05360-160.
} 


\section{INTRODUÇÃO}

$\mathrm{E}$ studos históricos, antropológicos e sociológicos demonstram a existência de variadas formas de compreender e relacionar-se com o uso de substâncias psicoativas em diferentes sociedades e culturas. A repressão, intolerância e condenação ao uso de substâncias psicoativas, que caracterizam atualmente nosso imaginário e práticas sociais, não estiveram presentes em outros períodos históricos (ESCAHOTADO, 1997; CARNEIRO, 2004).

Pode-se afirmar que as diferenças de classificação e tratamento dispensado às substâncias consideradas lícitas e ilícitas estão relacionadas mais aos contextos históricos, culturais, sociais e políticos do que às propriedades intrínsecas das substâncias. Se considerarmos apenas os aspectos biológicos ou propriedades farmacológicas de cada substância, não há elementos que justifiquem a permissividade e a legalidade do uso do álcool e do tabaco, por exemplo, como observado em algumas sociedades (ESCAHOTADO, 1997; CARNEIRO, 2004).

O uso das substâncias psicoativas é um problema discutido mundialmente, que mobiliza diversos setores das sociedades contemporâneas e que assumiu lugar central no debate público, principalmente por sua representação enquanto ameaça para a saúde pessoal e coletiva e por sua associação com a criminalidade e a violência urbana (SIMÕES, 2008).

No campo da saúde, essa discussão adquire especificidades no que tange à avaliação sobre os impactos do uso sobre a vida dos indivíduos e às diferenciações entre os padrões de consumo. Estabelecer essa diferenciação é importante, pois contribui para a desconstrução da concepção de que existem apenas duas categorias de sujeitos: os que não fazem uso de substâncias psicoativas e os dependentes. Para tal concepção, o uso de qualquer substância culmina necessariamente em dependência. Ao contrário, estudos diversos demonstram que diferentes tipos de consumo podem levar a problemáticas diferenciadas, dependendo do sujeito e do contexto onde este está inserido, e inspiram cuidados diferentes. Nota-se que a complexidade desta questão nem sempre é considerada e, para diversas abordagens neste campo, a diferenciação entre usuários e dependentes é associada à noção de "falta de limites", que pode ser influenciada pelo julgamento moral, construído socioculturalmente (SILVEIRA, 1996; MACRAE, 1997; FIORE, 2004).

Este artigo é parte integrante da dissertação de mestrado "Itinerários terapêuticos de sujeitos com problemáticas decorrentes do uso de álcool em um centro de atenção psicossocial", desenvolvida no programa de pós-graduação em Ciências da Reabilitação da FMUSP (MARQUES, 2010). Tem por objetivo apresentar a construção histórica de conceituações e modelos teóricopráticos relacionadas à questão do uso prejudicial de álcool e outras substâncias psicoativas, problematizando o uso destas concepções na formulação de abordagens de atenção e cuidado à saúde dos sujeitos que se encontram diante de tal questão.

\section{Definições, classificações e conceitos}

A problematização sobre o uso de substâncias psicoativas foi assumida pela medicina a partir do século XIX. Anteriormente, o uso de álcool e outras drogas psicoativas podia ser considerado ora uma prática condenável ora virtuosa em alguns aspectos, sem manter relação com a idéia de patologia (CARNEIRO, 2002; CRUZ, 2005).

$\mathrm{Na}$ literatura médica, a primeira referência ao conceito de dependência de álcool, mais especificamente, data de 1804, quando foi formulada a nova entidade nosográfica, o "hábito da embriaguez", que passou a ser considerado como doença mental (BERRIDGE, 1994; CARNEIRO, 2002).

Dessa forma, contrariando as explicações morais ou religiosas, o ato de beber em excesso foi assumido como uma questão médica e explicado pelas teorias da hereditariedade e da degeneração, assim como outras formas de adoecimento psíquico. Para os sujeitos considerados como "bebedor-problema", eram imputados diversos adjetivos e classificações médicas e a essa nova doença foram agregados as noções de degeneração física e aspectos morais, culturais e raciais que demarcavam, negativamente, o "caráter" do bebedor. Os primeiros tratamentos propostos se baseavam no confinamento compulsório, pouco diferindo da abordagem punitiva e moralista construída e aplicada para esta questão (BERRIDGE, 1994; CARNEIRO, 2002; FIORE, 2004; CRUZ, 2005).

Para Berridge (1994), mais importante do que a formulação dos conceitos de vício ou dependência, a novidade do século XIX foi a "conjunção de forças políticas, culturais e sociais que deu hegemonia a esses conceitos". Ao longo do século XIX e início do século XX, foi possível perceber a crescente intervenção do Estado sobre a disciplinarização dos corpos e medicalização 
das populações. Os ideais da "Higiene Social" da época pretendiam evitar a deterioração racial que se acreditava ser causada pelos degenerados hereditários, entre os quais se incluíam os "viciados" e os "bêbados" (CARNEIRO, 2002).

Nesse período, diversos países adotaram uma postura repressiva ao uso de álcool e outras substâncias psicoativas. Da mesma forma como se almejava a erradicação das doenças contagiosas, buscou-se a extinção do "vício", que culminou no movimento denominado "Ideologia da Temperança". Nos Estados Unidos, este ciclo foi iniciado pela perseguição ao consumo do ópio na Califórnia, passou pela campanha contra a cocaína e a primeira lei contra esta substância ("Harrison Act", de 1914), e chegou à aprovação do "Volstead Act", conhecido como "Lei Seca", que vigorou de 1919 a 1933 e que proibia a venda, distribuição e consumo de bebidas alcoólicas em todo o território norte-americano (CARNEIRO, 2002; ARAÚJO; MOREIRA, 2006).

No início do século XX, as noções sobre o modelo orgânico começaram a ser criticadas. Esse período marcou o advento e ampliação da influência da Psicanálise e outras correntes psicológicas (CARNEIRO, 2002). A Psicanálise despontou como importante modelo compreensivo, contrapondo-se à idéia da explicação exclusivamente biológica, e as então denominadas "toxicomanias" foram incorporadas na mesma categoria psicopatológica das perversões sexuais e dos transtornos de caráter (personalidades psicopáticas ou sociopatias) (SILVEIRA, 1996; CRUZ, 2005). No decorrer deste mesmo século, a medicina, psicologia e biologia passaram a progressivamente a considerar e sistematizar a dependência de álcool e outras drogas psicoativas como uma entidade nosológica específica, que poderia ser diagnosticada independentemente dos critérios morais e raciais (FIORE, 2004).

O termo "alcoolismo" foi utilizado pela primeira vez em 1849, pelo médico sueco Magnus Huss (apud NÓBREGA, 1996), que o descreveu como uma "enfermidade crônica", que afetava o sistema nervoso central e outros órgãos. A essa definição foram incorporados outros sentidos. À noção de "patologia", foram agregadas, entre outras, as de "vício", "fraqueza moral", "problema de comportamento" (NÓBREGA, 1996).

Em 1960, Jellinek (apud NÓBREGA, 1996) ampliou a definição: "alcoolismo é qualquer uso de bebidas alcoólicas que ocasiona prejuízo ao individuo, à sociedade ou a ambos". Esse autor compreendia o alcoolismo como um transtorno heterogêneo e distinguiu cinco "subtipos", baseado na crença de que esta classificação poderia facilitar a elaboração de estratégias de tratamento e profilaxias mais especificas.

Na década de 1970, Edwards e Gross observaram um repetido agrupamento de sinais e sintomas em indivíduos que faziam um uso "excessivo" de álcool e sugeriram a conceituação de "síndrome de dependência de álcool", que poderia ser definida a partir dos seguintes elementos: estreitamento do repertório de beber; saliência ou prioridade do beber sobre outras atividades; aumento da tolerância ao álcool; sintomas de abstinência; alívio dos sintomas de abstinência por ingestão do álcool; percepção subjetiva da compulsão para beber e reinstalação da síndrome após um período de abstinência (EDWARDS, 1995; NÓBREGA, 1996).

Em 1978, na 9a Revisão da Classificação Internacional de Doenças (CID-9), a OMS propôs a substituição do termo "alcoolismo" por "abuso do álcool sem dependência" e "síndrome de dependência do álcool". A nova definição buscou diferenciar os quadros estabelecidos a partir da estratificação dos padrões de consumo (OMS, 1978; NÓBREGA, 1996).

Na revisão seguinte, a CID-10, a expressão "abuso" ou "uso nocivo" passou a caracterizar o modo de consumo de uma substância psicoativa, que pode ser prejudicial para a saúde, e cujas complicações podem ser físicas ou psíquicas. A denominada "síndrome de dependência" foi definida como:

Conjunto de fenômenos comportamentais, cognitivos e fisiológicos que se desenvolvem após repetido consumo de uma substância psicoativa, tipicamente associado ao desejo poderoso de tomar a droga, à dificuldade de controlar o consumo, à utilização persistente apesar das suas conseqüências nefastas, a uma maior prioridade dada ao uso da droga em detrimento de outras atividades e obrigações, a um aumento da tolerância pela droga e por vezes, a um estado de abstinência física (OMS, 1993).

Assim como as classificações propostas pela OMS, a Associação Psiquiátrica Americana (APA) tem influenciado diretamente a conceituação dos fenômenos relativos ao uso de psicoativos. Tanto a CID-10 quanto a DSM-IV apresentam critérios diagnósticos semelhantes, diferenciando-se, basicamente, no uso de algumas terminologias. Essas classificações utilizam uma definição mais ampla do que as anteriores: abrangem as dimensões biológica, social e comportamental e apresentam, como aspecto principal, a perda do controle sobre o uso da substância (OMS, 1993; APA, 1995; CRUZ, 2005). 


\section{Modelos compreensivos}

Apesar dos esforços em se encontrar uma conceituação padrão, existem ainda muitas divergências nos modos de compreender o uso prejudicial de álcool e outras substâncias psicoativas. Para alguns autores, tratase de uma patologia, uma entidade nosológica distinta e autônoma, enquanto para outros representa um sintoma de uma desorganização psíquica, que pode estar relacionada a outras patologias, como depressão ou transtornos ansiosos. Os fatores envolvidos (biológicos, psicológicos e/ou sociais) podem ser tratados como causadores ou influenciadores, ou entendidos dentro de um contexto de interação complexa, cuja separação se torna simplista e artificial (FIGLIE et al., 2004; SILVEIRA; MOREIRA, 2006).

Visando à sistematização das abordagens teóricas sobre a questão das drogas, na literatura se pode observar diferentes propostas de categorização de modelos sobre o uso prejudicial de substâncias psicoativas. Nowlis (apud ACSELRAD, 2005; CRUZ, 2005) identificou quatro modelos, que se diferenciam nas posições assumidas e no enfoque dado às variáveis "droga", "sujeito" e "contexto sócio-cultural":

a) modelo jurídico-moral, que objetiva resolver o problema do uso de drogas impedindo o acesso e a utilização, por meio da repressão; promove a separação entre drogas lícitas das ilícitas e se concentra no controle das últimas, apoiando-se na tradição e na divulgação social de idéias que podem ser muitas vezes preconceituosas; considera que todos os indivíduos podem se tornar dependentes; o contexto sócio-cultural é visto como permissivo, por isso sugere-se a importância de rigidez na abordagem da questão;

b) modelo médico-sanitário, que busca construir explicações relaciona,das à ação das drogas no sistema nervoso central. Traz avanços importantes para o tratamento, mas mantém, como o modelo jurídico, a ênfase na substância, que tem ação determinante enquanto os indivíduos são vistos como vulneráveis e "indefesos";

c) modelo psicossocial, que compreende os usos de drogas como comportamentos humano, complexos e delimitados por determinados contornos sociais e culturais. Enfatiza a relação do indivíduo com a substância, no contexto em que vive, em sua particular história de vida;

d) modelo sociocultural, o qual sugere que as sociedades humanas sempre utilizaram substâncias psicoativas e que cada grupo social, em dado momento histórico, é quem define seus usos e suas interdições. Sugere a promoção de transformações no contexto social, considerado responsável por comportamentos identificados e nomeados como desviantes, ao invés de propor a "adequação" do indivíduo ao meio.

Tomados isoladamente, tais modelos não são suficientes para a compreensão dessa problemática nem para a definição de abordagens. Cruz (2005) recomenda que as abordagens terapêuticas nesse campo procurem "articular aspectos e desenvolver práticas que utilizem recursos adequados desses modelos".

\section{CONSIDERAÇÕES FINAIS}

Apesar de todas as contradições e até algumas inconsistências na conceituação e na determinação do diagnóstico da dependência, muito se tem avançado na formulação de teorias compreensivas relacionadas à dependência de substâncias psicoativas e na elaboração de estratégias de atenção e cuidado.

Contudo, Cruz (2005) chama atenção para o fato de que há mudanças importantes na elaboração de abordagens voltadas para os usuários de substâncias psicoativas, a partir da compreensão das dependências como uma questão médica, e não moral. Ainda assim, deve-se tomar cuidado para que o modelo de doença não reforce uma atitude de não implicação e passividade do sujeito que, como "doente", é desresponsabilizado por seus atos durante o uso de psicoativos, bem como por seu tratamento: "é preciso ir além, considerando as toxicomanias problemas de saúde, incluindo seus aspectos médicos, psicodinâmicos e socioculturais" (CRUZ, 2005).

Para o campo de atenção e cuidado em saúde, torna-se de grande relevância a formulação de práticas que integrem todos os aspectos envolvidos na experiência de uso e dependência, buscando compreender tal questão a partir da complexidade que esta apresenta. È importante considerar as especificidades nas trajetórias de cada sujeito que procuram atendimento nos diversos serviços e o singular cuidado de que necessita. Ademais, os profissionais que atuam na área nem sempre assumem o compromisso com a afirmação e garantia dos direitos de cidadania dos sujeitos atendidos (ACSERALD, 2009), sendo este um importante desafio na atual construção de práticas neste campo. 
MARQUES, A. L. M.; MÂNGIA, E. F. A. The construction of concepts of harmful use and dependence of alcohol: some considerations to the field of health attention and care. Rev. Ter. Ocup. Univ. São Paulo, v. 21, n. 1, p. 10-14, jan./abr. 2010.

\begin{abstract}
This paper aims to present a brief history about the process of conceptualization of the considered harmful use and dependence of alcohol, on the health field. In this way, intend to provide some elements to discuss the appropriation and the use of such concepts and of some theoretical-practical models related to this problem, on the process of formulation of health attention and care practices to the individuals with problems in consequence of substances use.
\end{abstract}

KEY WORDS: Substance-related disorders. Alcoholism.

\title{
REFERÊNCIAS
}

ACSELRAD G. A educação para a autonomia: construindo um discurso democrático sobre as drogas. In: ACSELRAD, G. (org.). Avessos do prazer: drogas, aids e direitos humanos. 2a ed. Rio de Janeiro: Fiocruz, 2005. p.183-212.

ARAÚJO, M. R.; MOREIRA, F. G. Histórias das drogas. In: SILVEIRA, D. X.; MOREIRA, F. G. (orgs.). Panorama atual de drogas e dependências. São Paulo: Atheneu, 2006.

ASSOCIAÇÃO DE PSIQUIATRIA AMERICANA. Manual diagnóstico e estatístico de transtornos mentais (DSM-IV). 4a. ed. Porto Alegre: Artes Médicas, 1995.

BERRIDGE, V. Dependência: história dos conceitos e teorias. In: EDWARDS, G.; LADER, M. (orgs.). A natureza da dependência das drogas. Porto Alegre: Artes Médicas, 1994.p.13-34.

CARNEIRO, H. A fabricação do vício. 2002. Disponível em: http://www.neip.info

CARNEIRO, H. Bebidas alcoólicas e outras drogas da época moderna. Economia e embriaguez do século XVI ao XVIII. Historiador Eletrônico, 2004. Disponível em: http://www.neip. info

CRUZ, M. Práticas médicas, toxicomanias e a promoção do exercício da cidadania. In: ACSELRAD, G. (org.). Avessos do prazer: drogas, aids e direitos humanos. $2 \mathrm{a}$ ed. Rio de Janeiro: Fiocruz, 2005. p.277-288.

EDWARDS, G. O tratamento do alcoolismo. Tradução de José Manoel Bertolote. 2a ed. São Paulo: Martins Fontes, 1995.

ESCAHOTADO, A. A proibição: princípios e conseqüências. In: RIBEIRO, M. M.; SEIBEL, S. D. (orgs.). Drogas: hegemonia do cinismo. São Paulo: Ed. Memorial, 1997. p. 29-46.

FIGLIE, N. B.; BORDIN, S.; LARANJEIRA, R. (orgs.). Aconselhamento em dependência química. São Paulo: Roca,
2004.

FIORE, M. Tensões entre o biológico e o social nas controvérsias médicas sobre uso de "drogas". In: REUNIÃO ANUAL DA ANPOCS, 28a. Anais. Caxambu, 2004. Disponível em: http:// www.neip.info

MARQUES, A. L. M. Itinerários terapêuticos de sujeitos com problemáticas decorrentes do uso de álcool em um centro de atenção psicossocial. Dissertação (mestrado). Faculdade de Medicina, Universidade de São Paulo, 2010.

NÓBREGA, A. A. N. Alcoolismo. In: SILVEIRA, D. X.; GORGULHO, M. Dependência: compreensão e assistência das toxicomanias. São Paulo: Ed. Casa do Psicólogo, 1996. p.105126.

ORGANIZAÇÃO MUNDIAL DE SAÚDE. Classificação Internacional de Doenças. 9a ed. São Paulo: OMS/OPS, 1978.

ORGANIZAÇÃO MUNDIAL DE SAÚDE. Classificação Internacional de Doenças. $10^{\mathrm{a}}$ ed. Porto Alegre: Artes Médicas, 1993.

SILVEIRA, D. X.; MOREIRA, F. G. Panorama atual de drogas e dependências. São Paulo: Atheneu, 2006.

SILVEIRA, D. X. Dependências: de que estamos falando, afinal? In: SILVEIRA, D. X.; GORGULHO, M. Dependência: compreensão e assistência das toxicomanias. São Paulo: Ed. Casa do Psicólogo; 1996. p. 1-14.

SIMÕES, J. A. Prefácio. In: LABATE B. C.; et al. (orgs.). Drogas e cultura: novas perspectivas. Salvador: EDUFBA, 2008.

VELHO, G. Drogas, níveis de realidade e diversidade cultural. In: RIBEIRO, M. M.; SEIBEL, S. D. (orgs.). Drogas: hegemonia do cinismo. São Paulo: Ed. Memorial, 1997. 